\title{
Effect of Nitroglycerin and Dipyridamole on Regional Left Ventricular Blood Flow during Coronary Artery Occlusion
}

\author{
LEWIS C. BECKER \\ From the Department of Medicine, University of North Carolina School of Medicine, Chapel Hill, \\ North Carolina 27514 and Johns Hopkins University School of Medicine, \\ Department of Medicine, Baltimore, Maryland 21205
}

A B S T R A C T Coronary vasodilators have been variously reported to increase, decrease, or have no effect upon blood flow to ischemic myocardium. Consequently, the effects of two different types of dilators, nitroglycerin (TNG) and dipyridamole, were studied with radioactive microspheres in open-chested dogs after coronary artery ligation. Given as a bolus i.v. injection, $0.4 \mathrm{mg}$ TNG resulted in an increase in blood flow to nonischemic areas of myocardium and a preservation of flow to ischemic regions, despite a fall in blood pressure. 5 min later blood pressure and nonischemic flow were back to base line, and a small selective increase in flow to ischemic myocardium was found $(0.15-0.18 \mathrm{ml} / \mathrm{min}$ per $\mathrm{g}, P<0.05)$. During an $0.2 \mathrm{mg} / \mathrm{min}$ infusion of TNG, and also after $1 \mathrm{mg} / \mathrm{kg}$ i.v. dipyridamole, ischemic flow was maintained in the face of a $20-30 \%$ reduction in blood pressure. In this setting, nonischemic flow was unchanged during TNG and doubled after dipyridamole. With the addition of methoxamine in both dilator groups, blood pressure returned to base line while flow to ischemic areas increased above base-line values (TNG, $0.16-0.20 \mathrm{ml} / \mathrm{min}$ per $\mathrm{g}, P<0.01$; dipyridamole, $0.18-$ $0.31 \mathrm{ml} / \mathrm{min}$ per $\mathrm{g}, P<0.05)$. Epicardial ST segment elevations increased during TNG infusion and were unchanged after dipyridamole, but with addition of methoxamine, ST segments became less elevated in both drug groups, concomitant with the observed increase in collateral blood flow. These data indicate that both types of coronary vasodilators, when used in conjunction with methoxamine to support blood pressure, reduce collateral resistance, increase collateral flow, and reduce epicardial ST-segment elevations.

Received for publication 27 May 1976 and in revised form 25 August 1976.

\section{INTRODUCTION}

Coronary vasodilators increase myocardial blood flow in hearts with normal coronary arteries and may also increase flow when coronary artery occlusive disease is present (1). However, in the latter situation, increased flow may merely be going to myocardial regions fed by normal vessels rather than areas supplied by obstructed vessels. While some investigators have found that vasodilators increase flow to compromised myocardium (2-8), others have found a decrease or no change (9-14). Fam and McGregor (11) have pointed out that these discrepancies may be related in part to differences in action among the various coronary dilators. Nitrates (e.g. nitroglycerin), which effect mainly large epicardial conductive arteries, may selectively increase flow to ischemic areas, while nonnitrate dilators (e.g. dipyridamole), which affect primarily small precapillary resistance vessels, may decrease flow in areas of myocardial ischemia by dilating arterioles in nonischemic areas ("coronary steal").

The purpose of this paper was to study in more detail the effects of cornary vasodilators on left ventricular blood flow distribution during regional myocardial ischemia. Radioactive microspheres were used to separate subendocardial and subepicardial flows in ischemic and normal regions. Measurements were made during drug-induced hypotension and repeated after blood pressure had been returned to base line with the alpha-adrenergic agonist methoxamine.

\section{METHODS}

30 mongrel dogs weighing 16-25 kg were anesthetized with sodium pentothal, $25 \mathrm{mg} / \mathrm{kg}$, followed by $0.4 \mathrm{~cm}^{3} / \mathrm{kg}$ of mixture containing $10 \mathrm{~g}$ alphachloralose in $100 \mathrm{~cm}^{3}$ polyethylene glycol 400. Supplemental doses of the chloralose mixture were given as necessary. Respiration with room air was maintained by Harvard pump (Harvard Apparatus Co., Inc., Millis, Mass.) and cuffed endotracheal tube. The heart was 
exposed through a left thoracotomy. Aortic and left atrial pressures and heart rate were monitored continuously. Cardiac output was measured by indocyanine green dilution with left atrial injection ( $2 \mathrm{mg}$ dye), femoral artery sampling (Gilford densitometer, $43 \mathrm{ml} / \mathrm{min}$, Gilford Instruments Laboratories, Inc., Berlin, Ohio), and a dynamic calibration technique (15). Calibration and experimental curves were adjusted to approximately the same height. In five dogs an insulated wire was sutured to left atrial appendage for pacing. With limited dissection, ligatures were passed around the anterior descending cornary artery (LAD) ${ }^{1}$ or most of its major branches.

Regional left ventricular blood flow was measured with radioactive microspheres. The method is based on the principle that microspheres injected into the left atrium distribute systemically in proportion to blood flow and because of their size are trapped in precapillary arterioles in their first passage through the circulation. The number of particles in any region of myocardium, reflected by the radioactivity, is proportional to flow. The microspheres used were mainly $15 \pm 5 \mu \mathrm{m}$ in diameter, obtained from the $3 \mathrm{M} \mathrm{Co}$. (Minneapolis, Minn.) as $1 \mathrm{mCi}$ of nuclide suspended in $10 \mathrm{~cm}^{3}$ of $10 \%$ dextran with one drop of Tween 80 to minimize clumping. They were labeled with one of the gamma-emitting nuclides ${ }^{169} \mathrm{Yb},{ }^{141} \mathrm{Ce}$, or ${ }^{85} \mathrm{Sr}$. In some experiments, spheres of $8-10 \mu \mathrm{m}$ diameter labeled with ${ }^{141} \mathrm{Ce},{ }^{51} \mathrm{Cr}$, or ${ }^{46} \mathrm{Sc}$ were used (described below). Slightly higher ratios of inner wall to outer wall radioactivity have been found with $15 \mu \mathrm{m}$ spheres than with $8-10 \mu \mathrm{m}$ spheres or diffusible indicators (16). However, the differences have been small, and all of these tracers appear to measure full thickness flows and directional flow changes equally well (16).

The extent and degree of myocardial ischemia was estimated from ST-segment elevation in epicardial electrocardiograms (17). These were recorded at $10-15$ sites on the anterior left ventricular surface at vessel bifurcations to allow easy relocation. A 0.01-inch diameter, insulated, braided stainless steel wire was attached to the $\mathrm{V}$ lead of a standard electrocardiograph. A 1-mm loop in the end was held manually against the epicardial surface with just enough pressure to produce minimal distortion in the wire. Elevation of the ST segment was measured from the base line to a point on the ST segment $0.10 \mathrm{~s}$ after the onset of ventricular activation at a standardization of $1 \mathrm{mV} / \mathrm{mm}$. Recordings were made at each site before cornary artery ligation and just after each microsphere injection. The ST-segment deviation present before ligation was subtracted from that present afterwards to determine the change due to ischemia. Sites with more than $2 \mathrm{mV}$ ST elevation before coronary occlusion were seen occasionally (usually related to coronary artery manipulation) and were excluded. An index of ischemia corresponding to each blood flow measurement was obtained by summing the significant ST elevations $(>2 \mathrm{mV})$ present in each dog ( $\Sigma$ ST).

After control hemodynamic and electrocardiographic measurements, diagonal branches of the LAD or the LAD itself were ligated. 60 min later a "control" blood flow measurement was made for each dog by injecting 1-2 million spheres labeled with ${ }^{169} \mathrm{Yb}$ into the left atrium in $5 \mathrm{ml}$ saline over 5-10 s and flushing the catheter with an additional $3 \mathrm{ml}$ saline. Before injection, the vial containing microspheres

\footnotetext{
${ }^{1}$ Abbreviations used in this paper: CCR, coronary collateral resistance; $\mathrm{HR}$, heart rate; $\mathrm{LAD}$, anterior descending coronary artery; MAP, mean arterial pressure; $\mathrm{MBF}$, myocardial blood flow; NICR, coronary resistance in nonischemic myocardium; OF, subepicardial flow in the ischemic region; SVR, system vascular resistance.
}

was vigorously agitated on a mechanical mixer for 1-2 min. Blood was simultaneously withdrawn from brachial and femoral arteries with a Harvard pump (Harvard Apparatus Co., Inc.) at $1.4 \mathrm{~cm}^{3} / \mathrm{min}$ for $3 \mathrm{~min}$, beginning just before microsphere injection. These collections were used to quantitate myocardial flow as described below.

In a group of $10 \mathrm{dogs}, 0.4 \mathrm{mg}$ nitroglycerin in $5 \mathrm{ml}$ saline was then given rapidly i.v. The nitroglycerin solution was prepared by dissolving a crushed sublingual tablet in saline. At the peak of hypotension, about $30 \mathrm{~s}$ after nitroglycerin, 1-2 million microspheres labeled with a second nuclide, ${ }^{141} \mathrm{Ce}(15 \mu \mathrm{m})$, were injected into the left atrium and reference blood samples collected. Although a true steady state was not present, it is likely that most of the microspheres reached myocardial and reference sites within the first $30 \mathrm{~s}$ while the blood pressure remained reduced (18). 5 min after nitroglycerin, when systemic hemodynamic changes had disappeared, a third set of microspheres labeled with ${ }^{85} \mathrm{Sr}$ was given.

In another group of eight dogs, nitroglycerin was given as an i.v. infusion. $1 \mathrm{~h}$ after ligation, after control injection of ${ }^{169} \mathrm{Yb}$ microspheres, $0.4 \mathrm{mg}$ nitroglycerin was given rapidly i.v. and a constant infusion of $0.2 \mathrm{mg}$ in $5 \mathrm{~cm}^{3}$ saline/min started with an infusion pump (Sigmamotor, Inc., Middleport, $\mathrm{N}$. Y.). $10 \mathrm{~min}$ later microspheres labeled with ${ }^{141} \mathrm{Ce}(15$ $\mu \mathrm{m})$ were given. While continuing nitroglycerin, an i.v. drip of methoxamine hydrochloride $\left(20 \mathrm{mg}\right.$ in $1,000 \mathrm{~cm}^{3}$ saline) was begun and titrated to bring the mean aortic blood pressure back to its prenitroglycerin level. This usually took 5- $10 \mathrm{~min}$. Microspheres labeled with ${ }^{85} \mathrm{Sr}$ were then given.

In another group of seven dogs the effects of the nonnitrate coronary vasodilator dipyridamole were studied. $1 \mathrm{~h}$ after coronary ligation ${ }^{169} \mathrm{Yb}$ microspheres were injected. $1 \mathrm{mg} / \mathrm{kg}$ dipyridamole was then given as an i.v. bolus and flow was measured $10 \mathrm{~min}$ later with ${ }^{141} \mathrm{Ce}(15 \mu \mathrm{m})$ spheres. The duration of action of a single i.v. bolus of dipyridamole has been shown to be greater than $15 \mathrm{~min}$ (19). The drug was obtained in ampules of $2 \mathrm{~cm}^{3}$ containing $10 \mathrm{mg}$ dipyridamole, $4 \mathrm{mg}$ tartaric acid, and $100 \mathrm{mg}$ polyethylene glycol 600 (Boehringer-Ingelheim, Ltd., Elmsford, N. Y.). After adjustment of mean aortic blood pressure to the predrug level with i.v. methoxamine, flow was again measured with ${ }^{85} \mathrm{Sr}$ spheres (approximately $10 \mathrm{~min}$ after ${ }^{141} \mathrm{Ce}$ spheres).

In an additional group of dogs the effects of nitroglycerin and dipyridamole were studied at constant heart rate and mean aortic pressure. Flow was measured after 60 min of ischemia with $7-10 \mu \mathrm{m}{ }^{141} \mathrm{Ce}$ microspheres and epicardial electrocardiograms recorded. Three dogs were given nitroglycerin $0.4 \mathrm{mg}$ followed by an infusion of $0.2 \mathrm{mg}$ in $5 \mathrm{~cm}^{3}$ saline/min; two other dogs received a single i.v. injection of $1 \mathrm{mg} / \mathrm{kg}$ dipyridamole. After $10 \mathrm{~min}{ }^{51} \mathrm{Cr}(7-10$ $\mu \mathrm{m})$ spheres were injected and epicardial electrocardiograms repeated. Mean aortic pressure was adjusted to control levels with i.v. methoxamine and left atrial pacing was instituted to prevent a fall in heart rate below predrug levels. Flow measurements $\left(7-10 \mu \mathrm{m}^{46} \mathrm{Sc}\right.$ spheres) and epicardial electrocardiograms were performed again.

At the end of each experiment, the margins of cyanosis were determined visually and recorded relative to the epicardial vascular pattern, and the dogs were killed with potassium chloride. The free left ventricular wall was cut into 50-70 ordered pieces of $0.4-2.0-\mathrm{g}$ size. After discarding gross epicardial fat and blood vessels, each piece was subdivided into inner and outer halves, weighed, placed in plastic tubes and counted in a 3-inch well type scintillation counter (Nuclear Chicago, Searle Analytic Inc., Des Plaines, Ill.) at each of three energy windows characteristic for the nuclides used. The reference arterial bloods taken 
during microsphere injection were counted in aliquots in identical fashion. Geometrical differences between tissue and blood samples in the counting chamber were found to be unimportant. The activities of the three nuclides in each sample were separated by gamma spectrometry and the counts per gram of tissue computed for each. Myocardial blood flow, in milliliters per minute per gram, was calculated for each nuclide by the formula: $\mathrm{MBF}=\mathrm{Cm} \times \mathrm{RBF} / \mathrm{Cr}$, where $\mathrm{MBF}=$ myocardial blood flow, $\mathrm{Cm}=$ counts per gram in myocardial samples, $\mathrm{RBF}=$ reference blood flow (Harvard pump withdrawal rate), and $\mathrm{Cr}=$ counts in reference blood samples (obtained by averaging the total counts of the simultaneous brachial and femoral samples). This relation follows from the fact that microspheres adequately mixed in the left atrium distribute to myocardium and peripheral artery in proportion to the blood flow to each. The radioactivity of femoral and brachial artery samples differed by less than $20 \%$ in $65 / 71$ pairs and by less than $25 \%$ in $69 / 71$.

After the flow for each sample was calculated, maps of blood flow for the left ventricular free wall were constructed (20). An "ischemic region" was defined for each dog consisting of the samples within the distribution of the ligated arteries with flow less than $50 \%$ of the nonischemic posterior wall. Epicardial electrograms over this area generally showed elevated ST segments although isoelectric or depressed segments were sometimes present. The "nonischemic region" consisted of six to eight samples in the posterior left ventricular wall including the papillary muscle. Mean flows in inner and outer portions of each region were determined and compared before and after drug with each dog as its own control.

As defined, the ischemic region clearly contained a predominance of ischemic myocardium. Small amounts of normally perfused tissue may have been inadvertantly included, but probably not to a significant extent. Possible misinterpretations of flow data could result from inclusion of nonischemic tissue in the ischemic region. For example, a selective incease in flow to nonischemic myocardium might cause an apparent increase in the "ischemic region". The sampling method used here minimized these errors. Samples from the edge of the ischemic region were cut along the cyanotic margin to exclude normal-looking tissue. Samples with flow more than $50 \%$ of normal were excluded as being more likely to contain nonischemic muscle. In previous studies using this sampling technique, increases in nonischemic flow have been seen without concomitant increases in flow to ischemic regions $(21,22)$, suggesting a lack of significant overlap.

The accuracy of flow measurements using the microsphere technique has been found to depend on the number of spheres present in myocardial blood samples (18). Although individual samples often contained small numbers of spheres, pooled samples were used to determine average flows in ischemic and nonischemic regions. 70 of 75 pooled ischemic samples contained over 400 spheres (most over 1,000 ) and $68 / 75$ pooled nonischemic samples contained over 5,000 spheres. Reference blood samples always contained over 1,000 spheres. From these values, a precision of $10-15 \%$ (SD) in ischemic regions and $5-10 \%$ in nonischemic ones was estimated (18).

Systemic vascular resistance (SVR) was calculated by dividing the mean arterial pressure by the cardiac output. Right atrial pressure was considered small relative to arterial pressure and was omitted. An index of coronary resistance in nonischemic myocardium (NICR) was obtained by dividing mean arterial pressure by mean blood flow in the nonischemic region. Coronary collateral resistance (CCR) was calculated as the mean arterial pressure divided by the mean blood flow in the ischemic region. Peripheral coronary pressure was not measured and therefore not included in the calculation. Previous studies have shown peripheral coronary pressure to be relatively small and to change less than aortic pressure under a variety of circumstances (9)

Student's $t$ test, adapted for paired comparisons, was used to determine the statistical significance of differences.

\section{RESULTS}

General. $60 \mathrm{~min}$ after coronary artery ligation, flow in the distribution of the ligated arteries was reduced more in the center than at the edge (20). In nonischemic myocardium flow was slightly greater in the inner than the outer half of the ventricular wall, but in the ischemic region this relationship was reversed. (Table I). During the course of this experiment, 60-90 min after coronary artery ligation, flow distribution and electrocardiographic changes have been shown to be stable (21).

Nitroglycerin. After rapid intravenous administration of $0.4 \mathrm{mg}$ nitroglycerin, mean arterial pressure declined maximally by $29 \%$ at $35 \pm 5 \mathrm{~s}$ (SD); left atrial pressure also fell and heart rate increased. Meanwhile, blood flow to nonischemic myocardium rose significantly $(P<0.01)$ with similar increases to inner and outer halves of the ventricular wall. (Tables I, II). Despite the fall in blood pressure, mean flow to the ischemic region was maintained. There was a slight increase in inner wall flow and a slight decrease in outer wall flow, the difference between inner and outer being of borderline significance $(P<0.05)$. NICR and CCR decreased in all 10 dogs (Table III). 5 min after nitroglycerin, systemic hemodynamics and coronary resistance were back to base line, and flow to nonischemic tissue had returned to control. At this time a small (about 20\%) selective increase in flow to ischemic tissue was seen in both inner and outer halves. This flow increase was found in 8 of the 10 dogs; additionally, CCR remained below base line in 9/10 (Tables I-III).

ST-segment elevation in epicardial electrograms ( $\Sigma S T$ ) was followed serially in 9 of the 10 experiments. Initially, mean $\Sigma S T$ increased slightly from 35.6 $\pm 6.8 \mathrm{mV}(\mathrm{SEM})$ to $38.0 \pm 7.9 \mathrm{mV}$ after nitroglycerin $(t=1.23, P<0.3)$. Over the next $15 \mathrm{~min}$, $\Sigma S T$ decreased gradually; at $5 \mathrm{~min}$ it was $33.1 \pm 7.3 \mathrm{mV}$, at 10 $\min 30.7 \pm 7.4 \mathrm{mV}$, and at $15 \mathrm{~min} 28.6 \pm 7.2 \mathrm{mV}$. The values at 10 and $15 \mathrm{~min}$ were significantly less than control $(P<0.05, P<0.02$, respectively). At $15 \mathrm{~min}$, ¿ST was below ischemia base line in eight of nine dogs.

When nitroglycerin was given as a constant i.v. infusion, mean arterial pressure and SVR fell about $20 \%$ and heart rate increased slightly. Left atrial pressure, cardiac output, NICR, CCR, and flow to nonischemic tissue did not change. Despite the fall in blood pres- 
TABLE I

Effect of Nitroglycerin and Dipyridamole on Regional Left Ventricle Flow

\begin{tabular}{|c|c|c|c|c|c|c|c|}
\hline & & \multicolumn{3}{|c|}{ Ischemic region } & \multicolumn{3}{|c|}{ Nonischemic region } \\
\hline & & Inner & Outer & Full & Inner & Outer & Full \\
\hline & & \multicolumn{6}{|c|}{$\mathrm{cm}^{3 / m i n} / \mathrm{g}$ of myocardium (mean $\pm S E M$ ) } \\
\hline \multirow[t]{4}{*}{ (A) } & TNG bolus & & & & & & \\
\hline & Control & $0.10 \pm 0.03$ & $0.20 \pm 0.03$ & $0.15 \pm 0.02$ & $0.70 \pm 0.06$ & $0.63 \pm 0.08$ & $0.67 \pm 0.08$ \\
\hline & $30 \mathrm{~s}$ & $0.12 \pm 0.02$ & $0.19 \pm 0.03$ & $0.16 \pm 0.02$ & $1.09 \pm 0.16^{*}$ & $0.86 \pm 0.14^{*}$ & $0.98 \pm 0.15^{*}$ \\
\hline & $5 \mathrm{~min}$ & $0.12 \pm 0.02$ & $0.24 \pm 0.03 \ddagger$ & $0.18 \pm 0.02 \$$ & $0.75 \pm 0.09$ & $0.71 \pm 0.10$ & $0.73 \pm 0.09$ \\
\hline \multirow[t]{5}{*}{ (B) } & TNG infusion & & & & & & \\
\hline & Control & $0.11 \pm 0.02$ & $0.21 \pm 0.03$ & $0.16 \pm 0.02$ & $0.93 \pm 0.13$ & $0.84 \pm 0.13$ & $0.89 \pm 0.14$ \\
\hline & Infusion & $0.10 \pm 0.02$ & $0.18 \pm 0.02$ & $0.14 \pm 0.02$ & $0.85 \pm 0.15$ & $0.81 \pm 0.13$ & $0.83 \pm 0.15$ \\
\hline & Infusion & & & & & & \\
\hline & + methoxamine & $0.13 \pm 0.02 \ddagger$ & $0.26 \pm 0.04^{*}$ & $0.20 \pm 0.03^{*}$ & $1.02 \pm 0.21$ & $0.92 \pm 0.18$ & $0.97 \pm 0.20$ \\
\hline \multirow[t]{5}{*}{ (C) } & Dipyridamole & & & & & & \\
\hline & Control & $0.13 \pm 0.03$ & $0.22 \pm 0.04$ & $0.18 \pm 0.04$ & $0.77 \pm 0.08$ & $0.76 \pm 0.07$ & $0.76 \pm 0.07$ \\
\hline & Dipyridamole & $0.15 \pm 0.05$ & $0.16 \pm 0.04 \ddagger$ & $0.16 \pm 0.04$ & $1.50 \pm 0.35 \S$ & $1.44 \pm 0.32 \$$ & $1.47 \pm 0.33 \S$ \\
\hline & Dipyridamole & & & & & & \\
\hline & + methoxamine & $0.29 \pm 0.09 \S$ & $0.32 \pm 0.08$ & $0.31 \pm 0.08 \S$ & $2.53 \pm 0.51^{*}$ & $1.99 \pm 0.37 *$ & $2.26 \pm 0.42^{*}$ \\
\hline
\end{tabular}

Inner, outer, and full refer to flow in subendocardial and subepicardial halves and average flow throughout region, respectively. Section A is based on $10 \mathrm{dogs}, \mathrm{B}$ is based on $8 \mathrm{dogs}$, and $\mathrm{C}$ is based on 9 dogs $(7$ studied with 15- $\mu \mathrm{m}$ spheres at uncontrolled HR and 2 with $10-\mu \mathrm{m}$ spheres at constant HR).

Symbols indicate statistical significance vs. control $\left({ }^{*}=P<0.01,+=P<0.02, \S=P<0.05\right)$.

TNG, nitroglycerin.

sure, flow to ischemic myocardium was again maintained as with the bolus injection (Tables I-III). Methoxamine was then added to bring mean arterial pressure back to base line. SVR increased but CCR was unaffected. There was also an increase in left atrial pressure and cardiac output, and decrease in heart rate. The combination of nitroglycerin and methoxamine resulted in a small selective increase in flow to ischemic tissue; the increase was about $20 \%$ in both inner and outer halves and was associated

TABLE II

Hemodynamic Effects of Nitroglycerin and Dipyridamole

\begin{tabular}{|c|c|c|c|c|c|c|c|c|}
\hline & & SBP & DBP & MBP & LAP & HR & $\mathrm{CO}$ & SVR \\
\hline \multirow{4}{*}{ (A) } & TNG bolus & $m m \mathrm{Hg}$ & $m m \mathrm{Hg}$ & $m m \mathrm{Hg}$ & $m m H g$ & beats/min & liters/min & $U$ \\
\hline & Control & $126 \pm 6$ & $101 \pm 6$ & $109 \pm 6$ & $5.4 \pm 0.6$ & $106 \pm 7$ & & \\
\hline & $30 \mathrm{~s}$ & $95 \pm 9 *$ & $69 \pm 9^{*}$ & $77 \pm 9 *$ & $3.8 \pm 0.5^{*}$ & $128 \pm 9 *$ & & \\
\hline & $5 \mathrm{~min}$ & $123 \pm 7 \pm$ & $97 \pm 6 \ddagger$ & $106 \pm 6 \hbar$ & $5.5 \pm 0.7 \ddagger$ & $105 \pm 6 \ddagger$ & & \\
\hline \multirow[t]{5}{*}{ (B) } & TNG infusion & & & & & & & \\
\hline & Control & $129 \pm 8$ & $100 \pm 8$ & $110 \pm 8$ & $6.5 \pm 0.9$ & $108 \pm 8$ & $1.19 \pm 0.16$ & $102 \pm 12$ \\
\hline & Infusion & $104 \pm 6^{*}$ & $82 \pm 6^{*}$ & $88 \pm 6^{*}$ & $6.1 \pm 0.8$ & $117 \pm 8$ & $1.28 \pm 0.16$ & $75 \pm 8^{*}$ \\
\hline & Infusion & & & & & & & \\
\hline & + methoxamine & $131 \pm 9 \neq$ & $102 \pm 8 \ddagger$ & $113 \pm 8 \ddagger$ & $10.0 \pm 1.5^{*} \ddagger$ & $94 \pm 8 * t$ & $1.46 \pm 0.24$ & $93 \pm 17$ \\
\hline \multirow[t]{5}{*}{ (C) $\mathrm{I}$} & Dipyridamole & & & & & & & \\
\hline & Control & $113 \pm 6$ & $85 \pm 7$ & $96 \pm 6$ & $6.7 \pm 1.5$ & $124 \pm 6$ & $0.99 \pm 0.10$ & $106 \pm 17$ \\
\hline & Dipyridamole & $88 \pm 8^{*}$ & $54 \pm 8^{*}$ & $66 \pm 8^{*}$ & $6.0 \pm 0.8$ & $97 \pm 7^{*}$ & $0.99 \pm 0.05$ & $70 \pm 11^{*}$ \\
\hline & Dipyridamole & & & & & & & \\
\hline & + methoxamine & $116 \pm 6$ & $83 \pm 7 \ddagger$ & $96 \pm 6$ & $7.6 \pm 1.2 \ddagger$ & $88 \pm 5^{*}$ & $1.20 \pm 0.12$ & $87 \pm 12$ \\
\hline
\end{tabular}

CO, cardiac output; DBP, diastolic aortic pressure; LAP, mean left atrial pressure; MBP, mean aortic pressure; SBP, systolic aortic pressure; and SVR, systemic vascular resistance. Values are means \pm SEM.

* Indicates statistical significance vs. control.

\$ Indicates statistical significance vs. preceding line. Section C includes only the seven dogs with uncontrolled HR. 
with a reduction in collateral resistance below base line in all eight animals (Fig. 1). These changes are similar to those found $5 \mathrm{~min}$ after the bolus injection of nitroglycerin (Tables I-III).

During nitroglycerin infusion, mean $\Sigma S T$ increased significantly from $41.4 \pm 12.5$ (SEM) to $55.8 \pm 7.2 \mathrm{mV}$ $(P<0.05)$. With the addition of methoxamine $\Sigma S T$ decreased below ischemia base line in all eight dogs and mean $\Sigma$ ST fell to $25.3 \pm 8.4 \mathrm{mV}(P<0.02 \mathrm{vs}$. control).

From the blood flow maps, no specific pattern of flow increase in ischemic areas could be identified, although the marked variation in size and shape of ischemic regions made interpretation difficult. The problem was examined quantitatively by dividing the ischemic region into zones of "severe" and "moderate" ischemia. Samples with average flow $0-25 \%$ of posterior wall were classified as "severe" ischemia and pooled to determine flow before and after nitroglycerin. Samples with flow $26-50 \%$ of posterior wall were considered "moderate" ischemia and analyzed separately. Similarly, epicardial electrograms were separated into sites with predrug ST-segment elevation of 2-6 mV ("moderate") and $>6 \mathrm{mV}$ ("severe") (Table IV). 5 min after the nitroglycerin bolus, absolute flow was increased somewhat more in the moderate ischemic than the severe ischemic zone $(P<0.01$, unpaired $t$ test), but the percentage increases were similar (21.0\% and $21.7 \%$, respectively). ST-segment

TABLE III

Effects of Nitroglycerin and Dipyridamole on Coronary Resistance

\begin{tabular}{llc}
\hline $\begin{array}{l}\text { Coronary } \\
\text { collateral } \\
\text { resistance }\end{array}$ & $\begin{array}{c}\text { Nonischemic } \\
\text { coronary } \\
\text { resistance }\end{array}$ \\
\hline
\end{tabular}

(A) TNG bolus

$\begin{array}{lll}\text { Control } & 8.08 \pm 0.89 & 1.77 \pm 0.16 \\ 30 \mathrm{~s} & 5.75 \pm 0.92^{*} & 0.88 \pm 0.10^{*} \\ 5 \mathrm{~min} & 6.61 \pm 0.84^{*} & 1.60 \pm 0.14^{++}\end{array}$

(B) TNG infusion

$\begin{array}{lll}\text { Control } & 8.47 \pm 1.65 & 1.39 \pm 0.17 \\ \text { Infusion } & 7.63 \pm 1.23 & 1.20 \pm 0.13 \\ \begin{array}{l}\text { Infusion } \\ \quad+\text { methoxamine }\end{array} & 6.82 \pm 1.23 \ddagger^{+} & 1.43 \pm 0.28\end{array}$

(C) Dipyridamole

$\begin{array}{lll}\begin{array}{l}\text { Control } \\ \text { Dipyridamole }\end{array} & 6.59 \pm 1.13 & 1.29 \pm 0.09 \\ \begin{array}{l}\text { Dipyridamole } \\ + \text { methoxamine }\end{array} & 5.92 \pm 1.22 & 0.55 \pm 0.10^{*} \\ & 4.81 \pm 1.08 \ddagger^{+} & 0.54 \pm 0.11^{*}\end{array}$

Symbols indicate statistical significance vs. control $\left({ }^{*} P<0.01\right.$, I $P<0.05$ ).

+ Indicates significance vs. preceding line $\left(^{+}=P<0.05\right.$, $\left.{ }^{++}=P<0.01\right)$.
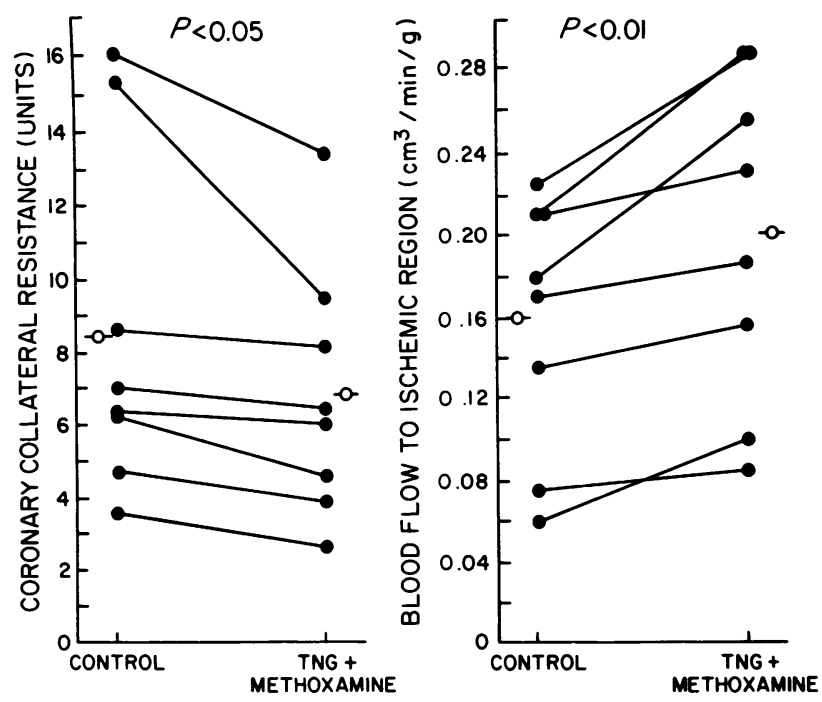

FIGURE 1 Effect of nitroglycerin (TNG) infusion on CCR (see text) and blood flow to ischemic myocardium. Mean aortic pressure adjusted to control levels with methoxamine infusion. Each represents an individual dog and $-\mathrm{O}-$ indicates mean value; $P$ refers to difference between means (paired $t$ test).

elevation was reduced similarly in both zones at 15 min. With the combination of nitroglycerin and methoxamine, flow increased to about the same extent in each zone, although ST segments were reduced more at sites with greater initial elevation $(P<0.01)$.

Dipyridamole. After dipyridamole, $1 \mathrm{mg} / \mathrm{kg}$ i.v., mean arterial pressure fell an average of $31 \%$ without significant changes in left atrial pressure or cardiac output. Heart rate fell $23 \%$, possibly related to a direct effect of the drug on the sinus node (11). Blood flow to nonischemic myocardium doubled, with approximately equal increases occurring in inner and outer halves of the ventricular wall. Despite the fall in blood pressure, flow to ischemic tissue fell only slightly; this decrease was confined to the subepicardial half of the wall. As a result the ratio of subendocardial to subepicardial flow (I/O) increased from 0.55 to $0.81(P<0.005)$. CCR decreased in seven of nine animals and increased in two, while the mean value did not change significantly. The two animals with an increase in CCR also had the greatest fall in mean arterial pressure $(80-30 \mathrm{~mm} \mathrm{Hg}$ and $88-$ $50 \mathrm{~mm} \mathrm{Hg}$ ).

When methoxamine was added to return mean arterial pressure to control, left atrial pressure increased and heart rate fell further, but NICR was unaffected (Tables II, III). Blood flow to nonischemic areas increased further to nearly three times control. Flow to ischemic tissue also increased significantly, averaging $72 \%$ above base line $(P<0.05)$. Increases were seen to both inner and outer halves of the wall, 
TABLE IV

Blood Flow and ST Segments in Severe and Moderate Zones of Ischemia

\begin{tabular}{|c|c|c|c|c|}
\hline & \multicolumn{2}{|c|}{ Severe zone } & \multicolumn{2}{|c|}{ Moderate zone } \\
\hline & $\begin{array}{c}\text { Flow } \\
(0-25 \%)\end{array}$ & $\begin{array}{l}\text { ST elevation } \\
(>6 \mathrm{mV})\end{array}$ & $\begin{array}{c}\text { Flow } \\
(26-50 \%)\end{array}$ & $\begin{array}{l}\text { ST elevation } \\
(2-6 \mathrm{mV})\end{array}$ \\
\hline & $\begin{array}{c}\mathrm{ml} / \mathrm{min} / \mathrm{g} \\
(\mathrm{mean} \pm \mathrm{SEM})\end{array}$ & $\begin{array}{c}m V \\
(m e a n \pm S E M)\end{array}$ & $\begin{array}{c}m l / m i n / g \\
(m e a n \pm S E M)\end{array}$ & $\begin{array}{c}m V \\
(m e a n \pm S E M)\end{array}$ \\
\hline $\begin{array}{l}\text { Ischemia } \\
\text { Ischemia + TNG bolus }\end{array}$ & $\begin{array}{l}0.09 \pm 0.01 \\
0.11 \pm 0.01 \\
P<0.001\end{array}$ & $\begin{array}{c}11.34 \pm 1.02 \\
9.59 \pm 0.93 \\
P<0.20\end{array}$ & $\begin{array}{l}0.27 \pm 0.01 \\
0.32 \pm 0.02 \\
P<0.001\end{array}$ & $\begin{array}{l}3.74 \pm 0.03 \\
2.95 \pm 0.51 \\
P<0.05\end{array}$ \\
\hline $\begin{array}{l}\text { Ischemia } \\
\text { Ischemia + TNG } \\
\quad \text { + methoxamine }\end{array}$ & $\begin{array}{l}0.14 \pm 0.01 \\
P<0.001\end{array}$ & $\begin{array}{l}8.50 \pm 0.94 \\
P<0.001\end{array}$ & $\begin{array}{l}0.36 \pm 0.02 \\
P<0.001\end{array}$ & $\begin{array}{l}2.83 \pm 0.31 \\
P<0.001\end{array}$ \\
\hline $\begin{array}{l}\text { Ischemia } \\
\text { Ischemia + dipyridamole } \\
\quad \text { + methoxamine }\end{array}$ & $\begin{array}{l}0.13 \pm 0.02 \\
P<0.005\end{array}$ & $\begin{array}{l}7.22 \pm 0.89 \\
P<0.001\end{array}$ & $\begin{array}{l}0.63 \pm 0.07 \\
P<0.001\end{array}$ & $\begin{array}{l}2.48 \pm 0.65 \\
P<0.02\end{array}$ \\
\hline
\end{tabular}

$P$ values refer to difference between pairs of values in each column. TNG, nitroglycerin.

with greater percentage increases in inner half (Table I). Flow increases to ischemic tissue were seen in 7/9 animals, concomitant with a reduction in CCR (Fig. 2).

After dipyridamole $\Sigma$ ST decreased in five dogs and increased in two, with no significant change in the mean value $(60.6 \pm 13.8 \mathrm{mV}$, SEM, to $51.9 \pm 9.2 \mathrm{mV})$. During the combination of dipyridamole and methox-
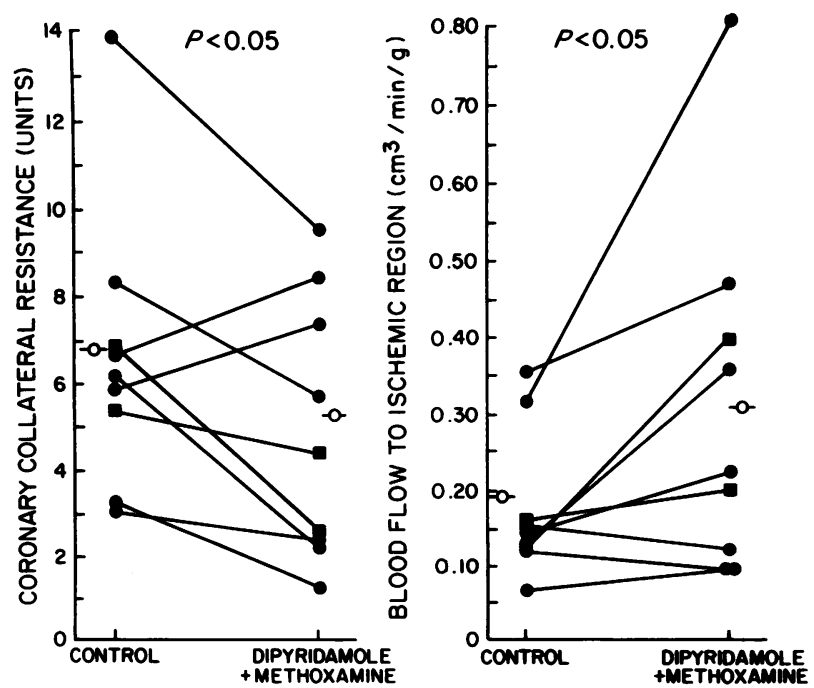

FIGURE 2 Effect of dipyridamole on CCR (see text) and fullwall blood flow to ischemic myocardium. Mean aortic pressure adjusted to control levels with methoxamine infusion. represents dogs with HR controlled by atrial pacing; animals where HR was allowed to fall. $-\mathrm{O}-$ indicates mean values and $P$ refers to difference between means (paired $t$ test). amine, $\Sigma S T$ decreased in all dogs and was less than base line in six of seven; mean $\Sigma S T$ fell to $34.1 \pm 7.4$ $\mathrm{mV}(P<0.05$ vs. control $)$.

Examination of blood flow maps showed that the increase in ischemic flow after dipyridamole tended to occur more at the periphery of the ischemic region than in the center. This was reflected in a greater increase in flow to the "moderate" ischemic than the "severe" ischemic zone $(P<0.001)$ (Table IV).

Effect of nitroglycerin and dipyridamole at constant heart rate and blood pressure. With atrial pacing and i.v. methoxamine, hemodynamic changes after nitroglycerin (three dogs) and dipyridamole (two dogs) were minimized. Average values for the five dogs included a heart rate of 124 beats $/ \mathrm{min}$ (control $=124$ beats/min), mean aortic pressure of $104 \mathrm{~mm} \mathrm{Hg}$ (control $=99 \mathrm{~mm} \mathrm{Hg}$ ), and mean left atrial pressure of 11.2 $\mathrm{mm} \mathrm{Hg}$ (control $=5.6 \mathrm{~mm} \mathrm{Hg}$ ). Flow to the ischemic region increased and collateral resistance decreased in all five dogs. Furthermore, ST-segment elevation fell in all five animals and mean $\Sigma$ ST decreased from 92.8 to $60.0 \mathrm{mV}$ (Fig. 3).

Multiple linear regression analysis was used to determine the quantitative relation between changes in ST-segment elevation, and changes in blood flow, heart rate, and blood pressure. Pooled data from the nitroglycerin infusion and dipyridamole experiments were used. When subepicardial flow in the ischemic region (OF) and heart rate (HR) were used as independent variables, changes in ST elevation could be predicted from the formula: $\Delta \mathrm{ST}=1.42(\Delta \mathrm{HR})$ $-0.76(\Delta \mathrm{OF})+11.38$, with $\Delta$ representing changes in each quantity expressed as a percentage. The overall

\section{2 L. C. Becker}


$F$ value for this relation was $19.55(P<0.001, r=0.77)$. Subepicardial flow was a better predictor than either subendocardial flow or full thickness flow although all three flows correlated inversely with ST height. ST segments could also be predicted from HR and mean arterial pressure (MAP) by the equation $\Delta \mathrm{ST}$ $=1.10 \quad(\Delta \mathrm{HR})-1.79 \quad(\Delta \mathrm{MAP})-15.17 \quad(r=0.78, \quad F$ $=21.58)$, since flow and arterial pressure were inversely related. Adding collateral resistance $(\Delta \mathrm{CCR})$ helped the prediction slightly: $\Delta \mathrm{ST}=1.18(\Delta \mathrm{HR})$

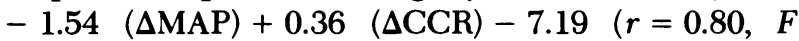
$=15.45)$.

\section{DISCUSSION}

Regional MBF. The major finding of this study was that both nitroglycerin and dipyridamole increased collateral blood flow and reduced CCR when used in combination with methoxamine. Given alone, both vasodilators caused a fall in coronary perfusion pressure by systemic vasodilatation, but flow to ischemic tissue did not fall proportionately, suggesting a reduction in the resistance to collateral flow.

Certain earlier studies indicated that coronary vasodilators could not improve perfusion of ischemic regions $(9,10)$. Vessels within ischemic areas were felt to be maximally dilated and the collateral vessels supplying flow were considered passive tubes incapable of vasomotion. However, more recent studies have shown that vasodilators may in fact increase collateral flow (Table V) and that the changes in flow depend on the relative changes in perfusion pressure and collateral resistance.

Although the two agents had similar effects on collateral flow, the overall pattern of response to nitroglycerin and dipyridamole differed. 5 min after a bolus injection, nitroglycerin caused a selective increase in flow to ischemic tissue and no change in flow to nonischemic areas. As an infusion, nitroglycerin caused no change in flow to either ischemic or nonischemic muscle, while dipyridamole caused an increase in nonischemic flow and a reduction in flow to ischemic subepicardium. With blood pressure support, flow to ischemic muscle was increased by both drugs, but nonischemic flow was increased only by dipyridamole. These disparities probably stem from dipyridamole's more potent small vessel dilating properties. Coronary arteriolar dilatation led to increased nonischemic flow, while more intense systemic arteriolar dilatation resulted in a greater fall in blood pressure and thereby a reduction in ischemic subepicardial flow.

Contrary to the present study, Fam and McGregor (11) found that nitroglycerin increased collateral flow only in dogs with "chronic ischemia" and welldeveloped collateral vessels; no increase was seen in dogs with acute coronary artery ligation. Dipyridamole

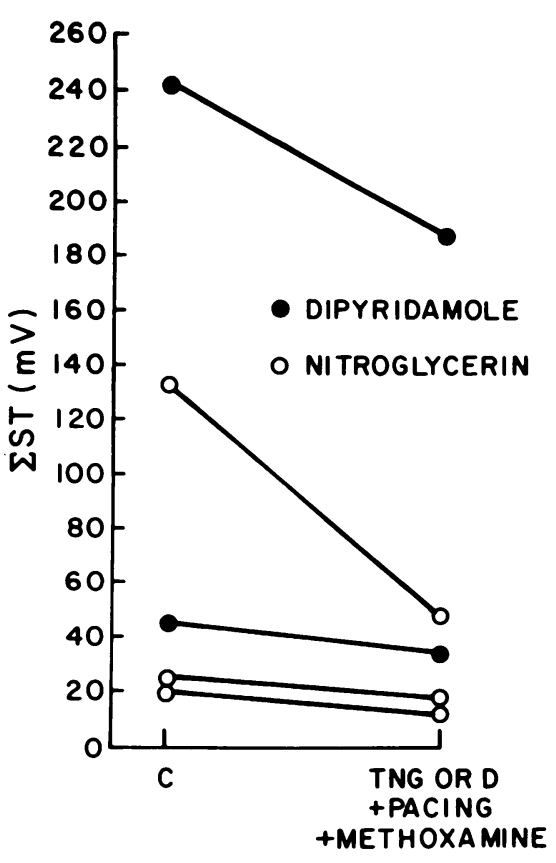

FIGURE 3 Effect of nitroglycerin (TNG) and dipyridamole (D) on $\Sigma S T$ at constant HR and mean aortic pressure.

failed to increase collateral flow in either preparation. Fam and McGregor's results may have been influenced by their use of dipyridamole for 5-6 mo in some of the animals, or their testing of nitroglycerin before dipyridamole in most of the experiments. Another possibility relates to the retrograde flow method they used. This technique appears to underestimate collateral flow compared with ${ }^{86} \mathrm{Rb}$ tracer uptake (23) or ${ }^{85} \mathrm{Kr}$ gas washout (8), particularly in ischemic subendocardium $(23,24)$.

Either direct or indirect cardiac effects could theoretically explain the increased collateral flow and reduced "collateral resistance" found here during vasodilator-methoxamine administration. Vasodilatorinduced decreases in left ventricular filling pressure could reduce the stretch on collateral vessels (10), but filling pressures, reflected in left atrial pressure, were actually unchanged or increased in this study. Reduced afterload could lead to improved contraction in ischemic myocardial segments (25) and could thereby affect local extravascular compressive forces; however, CCR was diminished even when aortic pressure was maintained constant by methoxamine. Ganz and Marcus (1) have shown that pacing-induced angina in man is relieved by intravenous but not intracoronary nitroglycerin, suggesting an indirect effect of the drug; however, it is difficult to know how far their results in man can be extrapolated to the present animal study.

It seems more likely that in this situation at least, a direct action on coronary vessels was involved. 
TABLE V

Effect of Coronary Dilators on Flow to Ischemic Myocardium

\begin{tabular}{|c|c|c|c|c|c|}
\hline References & Method & Subject & Dose/route & $\begin{array}{c}\text { Col- } \\
\text { lateral } \\
\text { flow }\end{array}$ & CCR \\
\hline \multicolumn{6}{|l|}{ Nitrates } \\
\hline Wiggers and Green, 1936 (9) & BF & $\mathrm{D}, \mathrm{A}$ & $\mathrm{NaNO}_{2}$, i.v. & NC & D \\
\hline Kattus and Gregg, 1959 (10) & BF & $\mathrm{D}, \mathrm{A}$ & TNG, $0.06 \mathrm{mg} / \mathrm{min}$, i.c. & NC & NC \\
\hline Leighninger et al., 1959 (2) & BF & $\mathrm{D}, \mathrm{A}$ & TNG, 0.6 mg, i.v. & I $20 \%$ & D \\
\hline Fam and McGregor, 1964 (11) & BF & $\mathrm{D}, \mathrm{A}$ & TNG, $0.6-0.9 \mathrm{mg}$, i.v./SL & D $16 \%$ & D \\
\hline Linder and Seeman, 1967 (12) & i.c. ${ }^{85} \mathrm{Kr}$ & $\mathrm{D}, \mathrm{A}$ & TNG, $0.02-0.3 \mathrm{mg} / \mathrm{kg}$, i.v./i.c. & D $20 \%$ & D \\
\hline Pasyk et al., 1971 (13) & i.c. ${ }^{133} \mathrm{Xe}$ & $\mathrm{D}, \mathrm{C}$ & TNG, 0.03-0.06 mg, i.c. & NC & ? \\
\hline Mathes and Rival, 1971 (3) & ${ }^{86} \mathrm{Rb}$ & $\mathrm{D}, \mathrm{A}$ & TNG, 0.05 mg/kg, i.v. & I $25 \%$ & D \\
\hline Horwitz et al., 1971 (4) & $\operatorname{depot}{ }^{133} \mathrm{Xe}$ & M, A & TNG, $0.4 \mathrm{mg}, \mathrm{SL}$ & I $25 \%$ & D \\
\hline Weisse et al., $1972(5)$ & i.c. ${ }^{85} \mathrm{Kr}$ & $\mathrm{D}, \mathrm{A}$ & ISD, $0.013 \mathrm{mg} / \mathrm{kg} / \mathrm{min}$, i.v. & I $53 \%$ & D \\
\hline Goldstein et al., 1974 (14) & BF & $\mathbf{M}, \mathbf{A}$ & TNG, $0.1 \mathrm{mg} / \mathrm{min}$, i.a. & NC & D \\
\hline \multicolumn{6}{|l|}{ Dipyridamole } \\
\hline Kiese et al., $1960(6)$ & $\mathbf{H}$ & D, A & $0.4 \mathrm{mg} / \mathrm{kg} / \mathrm{min}$, i.v. & I $30 \%$ & D \\
\hline Fam and McGregor, 1964 (11) & BF & $\mathrm{D}, \mathrm{A}$ & 5- $10 \mathrm{mg}$, i.v. & D & NC \\
\hline Linder and Seeman, 1967 (12) & i.c. ${ }^{85} \mathrm{Kr}$ & $\mathrm{D}, \mathrm{A}$ & $0.25-1.5 \mathrm{mg} / \mathrm{kg}$, i.v./i.c. & I $30 \%$ & D \\
\hline Rees and Redding, 1967 (7) & i.c. ${ }^{133} \mathrm{Xe}$ & $\mathrm{D}, \mathrm{A}$ & $0.5 \mathrm{mg} / \mathrm{kg}$, i.v. & $I^{*}$ & $\mathrm{D}^{*}$ \\
\hline Pasyk et al., 1971 (13) & i.c. ${ }^{133} \mathrm{Xe}$ & $D, C$ & $0.5-1 \mathrm{mg}$, i.c., $3-5 \mathrm{mg}$, i.v. & NC & $?$ \\
\hline Cibulski et al., 1972 (8) & i.c. ${ }^{85} \mathrm{Kr}$ & $\mathrm{D}, \mathrm{A}$ & $0.5 \mathrm{mg} / \mathrm{kg}$, i.v. & I $90 \%$ & $\mathrm{D} \ddagger$ \\
\hline
\end{tabular}

Values for CCR not explicitly given in references were estimated from available arterial pressure and collateral flow data.

Abbreviations: Under Method, BF, backflow; i.c., intracoronary; H, heat clearance; Under Subject, D, dog; M, man; A, anesthetized; C, conscious; Under Dose/Route, TNG, nitroglycerin; ISD, isosorbide dinitrate; SL, sublingual; i.a., intra-aortic; Under Collateral flow and CCR, NC, no change; I, increase; D, decrease.

* Changes seen from $24 \mathrm{~h}$ to 10 days after coronary artery ligation but not at $2 \mathrm{~h}$.

$\ddagger$ Changes seen in animals with chronic but not acute ischemia.

Arterioles within an ischemic region are probably already maximally dilated, but further dilatation might be possible in larger arteries (26) or capillaries ("recruitment") in the ischemic region (27), or in adjacent small arteries in nonischemic areas providing the source of collateral flow (28). There is also a possibility of direct dilatation of collateral vessels. Dipyridamole has been shown to enhance collateral development (29), an action which is difficult to explain except by direct effect on the collaterals themselves.

The alpha-adrenergic agonist methoxamine was used to maintain aortic pressure. Although methoxamine by itself reduces ischemic injury in experimental canine infarction (17), this beneficial action is probably related to hypertension and increased collateral flow (10). In our experiments blood pressure was returned to, but not above base-line levels. Addition to methoxamine in both vasodilator groups caused a fall in CCR, probably mediated through an increase in perfusion pressure with mechanical distension of collateral vessels (26). Methoxamine could possibly have also enhanced collateral flow by direct stimulation of alphareceptors in small coronary arteries distal to the origin of collateral vessels. Although these small arteries are thought to contain beta- rather than alpha- receptors (30), the exact point of transition of alphato beta-receptors along the course of an artery is unknown. Additionally, methoxamine could have indirectly increased collateral flow by stimulating a baroreceptor reflex (31). However, we observed no reduction in coronary resistance in nonischemic myocardium to suggest this mechanism, and it is unknown whether collateral vessels would actually be involved in this reflex.

Previous studies have suggested that nitrates may alter the transmural distribution of flow, although results have been conflicting. Nitroglycerin given i.v. during partial coronary occlusion $(3,19,32,33)$ and also before a short period of complete occlusion (34), caused a redistribution of flow toward the endocardium. Intracoronary injection of nitroglycerin caused a shift in the opposite direction (35). In the nonischemic heart, nitroglycerin resulted in no change in transmural flow (36). Dipyridamole has been studied less intensively, but caused subendocardial ischemia in one report (37) and no change in another (19). In the present study, nitroglycerin did not alter transmural flow distribution, but dipyridamole caused a significant shift of flow toward the subendocardium in ischemic areas. As suggested previously by Winbury 
et al. (19) for nitroglycerin, this may have been related to dilatation of small intramural perforating arteries by dipyridamole. It seems clear from these conflicting data that more work is needed to clarify the effects of coronary dilators on transmural flow.

Myocardial injury. Myocardial injury was assessed from ST-segment elevation in epicardial electrocardiograms (17). Although there may be theoretical objections that ST-segment shifts are not specific for myocardial ischemia (38), ST elevations have generally been correlated with other indices of ischemia, including reduced local blood flow (39), decreased tissue $\mathrm{PO}_{2}$ (40), abnormal myocardial metabolism (41), and reduced myocardial creatine phosphokinase $(17,39)$.

In the present study, nitroglycerin and dipyridamole both reduced ST-segment elevation when blood pressure was supported with methoxamine. Similar beneficial effects on ST-segment elevation have been reported for nitroglycerin in experimental animals with myocardial ischemia $(42,43)$ and patients with acute myocardial infarction (44). Additionally, nitroglycerin has been shown to increase myocardial $\mathrm{PO}_{2}$ during ischemia (19), improve function in ischemic segments $(25,28)$, and reduce myocardial necrosis in experimental infarction (45). However, adverse effects on ST-segment elevation may be seen when blood pressure falls excessively or reflex tachycardia occurs (45). Under these circumstances, collateral flow to the ischemic region may fall in the face of increasing myocardial oxygen demands.

At variance are the animal studies of Bleifeld et al. in which nitroglycerin failed to improve epicardial ST segments (46) and dipyridamole made them worse (47), even with stabilization of blood pressure. In these studies, coronary artery occlusion periods were shorter than ours and collateral vessels may therefore have been less functional. Also the dose of dipyridamole used was much lower and collateral blood flow was not measured.

Some of our ST-segment improvement may have been related to decreased myocardial oxygen demands. HR was significantly reduced (direct effect of dipyridamole [11] and indirect effect of methoxamine), although ventricular filling pressure was increased, and aortic pressure was kept at base-line levels. Changes in contractility were not measured but were probably small $(46,47)$. Most of the ST-segment improvement was probably due instead to increased collateral blood flow. Increased flow and decreased ST elevation were consistent findings after nitroglycerin-methoxamine and dipyridamole-methoxamine. When a decrease in heart rate was prevented by atrial pacing, ST-segment improvement and increased collateral flow were still seen. Multiple linear regression analysis suggested that flow and HR were both important factors.

\section{ACKNOWLEDGMENTS}

The author wishes to thank Stephen Guttu, Diane Buckner, and Rosemary Hopkins for their able assistance.

This investigation was supported, in part, by the North Carolina Heart Association grant-in-aid 1972-73-A-4 and the United Health Services of North Carolina Research grant VB 095 .

\section{REFERENCES}

1. Ganz, W., and H. S. Marcus. 1972. Failure of intracoronary nitroglycerin to alleviate pacing-induced angina. Circulation. 46: 880-889.

2. Leighninger, D. S., R. Rueger, and C. S. Beck. 1959. Effect of glyceryl trinitrate (nitroglycerin) on arterial blood supply to ischemic myocardium. Am. J. Cardiol. 3: 445-453.

3. Mathes, P., and J. Rival. 1971. Effect of nitroglycerin on total and regional coronary blood flow in the normal and ischaemic canine myocardium. Cardiovasc. Res. 5: 54-61.

4. Horwitz, L. D., R. Gorlin, W. J. Taylor, and H. G. Kemp. 1971. Effects of nitroglycerin on regional myocardial blood flow in coronary artery disease. J. Clin. Invest.50: 1578-1584.

5. Weisse, A. B., A. Senft, M. I. Kahn, and T. J. Regan. 1972. Effect of nitrate infusions on the systemic and coronary circulations following acute experimental myocardial infarction in the intact dog. Am. J. Cardiol. 30: $362-370$

6. Kiese, M., G. Lange, and K. Resag. 1960. Die Wirkung von 2,6-Bis (diathanolamino)-4,8-dipiperidino-pyrimido (5,4-d) pyrimidin auf die Durchblutung des experimentellen Herzinfarkts und des gesunden Herzmuskels. Z. Gesamte Exp. Med. 132: 426-435.

7. Rees, J. R., and V. J. Redding. 1967. Effects of dipyridamole on anastomotic blood flow in experimental myocardial infarction. Cardiovasc. Res. 1: 179-183.

8. Cibulski, A. A., P. H. Lehan, and H. H. Timmis. 1972. Retrograde flow technique vs. krypton-85 clearance technique for estimation of myocardial collaterals. Am. J. Physiol. 223: 1081-1087.

9. Wiggers, C. J., and H. D. Green. 1936. Ineffectiveness of drugs upon collateral flow after experimental coronary occlusion in dogs. Am. Heart J 11: 527-541.

10. Kattus, A. A., and D. E. Gregg. 1959. Some determinants of coronary collateral blood flow in the open-chest dog. Circ. Res. 7: 628-642.

11. Fam, W. M., and M. McGregor. 1964. Effect of coronary vasodilator drugs on retrograde flow in areas of chronic myocardial ischemia. Circ. Res. 15: 355-365.

12. Linder, E., and T. Seeman. 1967. Effects of persantin and nitroglycerin on myocardial blood flow during temporary coronary occlusions in dogs. Angiological (Basel). 4: 225-255.

13. Pasyk, S., C. M. Bloor, E. M. Khouri, and D. E. Gregg. 1971. Systemic and coronary effects of coronary artery occlusion in the unanesthetized dog. Am. J. Physiol. 220: 646-654.

14. Goldstein, R. E., E. B. Stinson, J. L. Scherer, R. P. Seningen, T. M. Grehl, and S. E. Epstein. 1974. Intraoperative coronary collateral function in patients with coronary occlusive disease. Nitroglycerin responsiveness and angiographic correlations. Circulation. 49: 298-308.

15. Völlm, K. R., and E. L. Rolett. 1969. Calibration of dye- 
dilution curves by a dynamic method. J. Appl. Physiol. 26: $147-150$.

16. Utley, J., E. L. Carlson, J. I. E. Hoffman, H. M. Martinez, and G. D. Buckberg. 1974. Total and regional myocardial blood flow measurements with $25 \mu, 15 \mu, 9 \mu$, and filtered $1-10 \mu$ diameter microspheres and antipyrine in dogs and sheep. Circ. Res. 34: 391-405.

17. Maroko, P. R., J. K. Kjekshus, B. E. Sobel, T. Watanabe, J. W. Covell, J. Ross, Jr., and E. Braunwald. 1971. Factors influencing infarct size following experimental coronary artery occlusions. Circulation. 43: 67-82.

18. Buckberg, G. D., J. C. Luck, D. B. Payne, J. I. E. Hoffman, J. P. Archie, and D. E. Fixler. 1971. Some sources of error in measuring regional blood flow with radioactive microspheres. J. Appl. Physiol. 31: 598-604.

19. Winbury, M. M., B. B. Howe, and H. R. Weiss, 1971. Effect of nitroglycerin and dipyridamole on epicardial and endocardial oxygen tension - further evidence for redistribution of myocardial blood flow. J. Pharmacol. Exp. Ther. 176: 184-199.

20. Becker, L. C., R. Ferreira, and M. Thomas. 1973. Mapping of left ventricular blood flow with radioactive microspheres in experimental coronary artery occlusion. Cardiovasc. Res. 7: 391-400.

21. Becker, L. C., R. Ferreira, and M. Thomas. 1975. Effect of propranolol and isoprenaline on regional left ventricular blood flow in experimental myocardial ischaemia. Cardiovasc. Res. 9: 178-186.

22. Becker, L. 1976. Effect of tachycardia on left ventricular blood flow distribution during coronary occlusion. Am. J. Physiol. 230: 1072-1077.

23. Levy, M. N., E. S. Imperial, and H. Zieske, Jr. 1961 Collateral blood flow to the myocardium as determined by the clearance on Rubidium ${ }^{86}$ chloride. Circ. Res. 9: 1035- 1043.

24. Downey, H. F., F. A. Bashour, A. J. Stephens, S. J Kechejian, and R. H. Underwood. 1974. Transmural gradient of retrograde collateral blood flow in acutely ischemic canine myocardium. Circ. Res. 35: 365-371.

25. Dove, J. T., P. M. Shah, and B. F. Schreiner. 1974. Effects of nitroglycerin on left ventricular wall motion in coronary artery disease. Circulation. 49: 682-687.

26. Cohen, M. V., and E. S. Kirk. 1973. Differential response of large and small coronary arteries to nitroglycerin and angiotensin. Autoregulation and tachyphylaxis. Circ. Res. 33: 445-453.

27. Hellberg, K., H. Wayland, A. L. Rickart, and R. J. Bing, 1972. Studies on the cornary microcirculation by direct visualization. Am. J. Cardiol. 29: 593-597.

28. Cohen, M. V., J. M. Downey, E. H. Sonnenblick, and E. S. Kirk, 1973. The effects of nitroglycerin on coronary collaterals and myocardial contractility. J. Clin. Invest. 52: 2836-2847.

29. Vineberg, A. M., R. S. Chari, R. Pifarre, and C. Mercier. 1962. The effect of persantin on intercoronary collateral circulation and survival during gradual experimental coronary occlusion: A preliminary report. Can. Med. Assoc. J. 87: 336-345.

30. Zuberbuhler, R. C., and D. F. Bohr. 1965. Responses of coronary smooth muscle to cathecolamines. Circ. Res. 16: 431-440.

31. Hackett, J. G., F. M. Abboud, A. L. Mark, P. G. Schmid, and D. D. Heistad. 1972. Coronary vascular responses to stimulation of chemoreceptors and baroreceptors. Evidence for reflex activation of vagal cholinergic innervation. Circ. Res. 31: 8-17.

32. Bache, R. J., R. M. Ball, F. R. Cobb, J. C. Rembert, and J. C. Greenfield, Jr. 1975. Effects of nitroglycerin on transmural myocardial blood flow in the unanesthetized dog. J. Clin. Invest. 55: 1219-1228.

33. Nakamura, M., Y. Etoh, N. Hamanaka, A. Kuroiwa, H. Tomoike, and Y. Ishihara. 1973. Effects of selective coronary hypotension and nitroglycerin or Bay a 1040 on the distribution of $\mathbf{R b}^{86}$ clearance in the canine heart. Cardiovasc. Res. 7: 777-788.

34. Becker, L. C., N. J. Fortuin, and B. Pitt. 1971. Effect of ischemia and antianginal drugs on the distribution of radioactive microspheres in the canine left ventricle. Circ. Res. 28: 263-269.

35. Forman, R., E. S. Kirk, J. M. Downey, and E. H. Sonnenblick. 1973. Nitroglycerin and heterogeneity of myocardial blood flow. Reduced subendocardial blood flow and ventricular contractile force. J. Clin. Invest. 52: 905911.

36. Fortuin, N. J., S. Kaihara, L. C. Becker, and B. Pitt. 1971. Regional myocardial blood flow in the dog studied with radioactive microspheres. Cardiovasc. Res. 5: 331-336.

37. Flameng, W., B. Wusten, and W. Schaper. 1974. On the distribution of myocardial flow, Part II: Effects of arterial stenosis and vasodilation. Basic Res. Cardiol. 69: 435-446.

38. Holland, R. P., and H. Brooks, 1975. Precordial and epicardial surface potentials during myocardial ischemia in the pig. A theoretical and experimental analysis of the TQ and ST segments. Circ. Res. 37: 471-480.

39. Kjekshus, J. K., P. R. Maroko, and B. E. Sobel. 1972 Distribution of myocardial injury and its relation to epicardial ST-segment changes after coronary artery occlusion in the dog. Cardiovasc. Res. 6: 490-499.

40. Sayen, J. J., W. F. Sheldon, G. Peirce, and P.T . Kuo. 1958. Polarographic oxygen, the epicardial electrocardiogram and muscle contraction in experimental acute regional ischemia of the left ventricle. Circ. Res. 6: 779-798

41. Karlsson, J., G. H. Templeton, and J. T. Willerson. 1973. Relationship between epicardial S-T segment changes and myocardial metabolism during acute coronary insufficiency. Circ. Res. 32: 725-730.

42. Smith, E. R., D. R. Redwood, W. E. McCarron, and S. E Epstein. 1973. Coronary artery occlusion in the conscious dog. Effects of alterations in arterial pressure produced by nitroglycerin, hemorrhage, and alpha-adrenergic agonists on the degree of myocardial ischemia. Circulation 47: 51-57.

43. Myers, R. W., J. L. Scherer, R. A. Goldstein, R. E. Goldstein, K. M. Kent, and S. E. Epstein. 1975. Effects of nitroglycerin and nitroglycerin-methoxamine during acute myocardial ischemia in dogs with pre-existing multivessel coronary occlusive disease. Circulation. 51: 632640.

44. Flaherty, J. T., P. R. Reid, D. T. Kelly, D. R. Taylor, M. L. Weisfeldt, and B. Pitt. 1975. Intravenous nitroglycerin in acute myocardial infarction. Circulation. 51: 132-139.

45. Hirshfeld, J. W., Jr., J. S. Borer, R. E. Goldstein, M. J. Barrett, and S. E. Epstein. 1974. Reduction in severity and extent of myocardial infarction when nitroglycerin and methoxamine are administered during coronary occlusion. Circulation. 49: 291-297.

46. Bleifeld, W., W. Wende, W. D. Bussmann, and J. Meyer. 1973. Influence of nitroglycerin on the size of experimental myocardial infarction. Nauyn-Schmiedeberg's Arch. Pharmacol. 277: 387-400.

47. Bleifeld, W., W. Wende, J. Meyer, and W. D. Bussmann 1974. Einfluss einer Vaso-Dilatation durch Dipyridamol auf die Grösse des akuten experimentellen Herzinfarktes. Z. Kardiol. 63: 115-128. 